INVESTIGACIÓN/RESEARCH Recibido:

\title{
DE LO VERNACULAR Y EL WORLD CINEMA EN BIUTIFUL
}

Lorenzo J. Torres-Hortelano ${ }^{1}$ : Universidad Rey J uan Carlos. España. lorenzojavier.torres.hortelano@urjc.es

\section{RESUMEN}

Mi objetivo en este artículo es analizar textualmente algunas imágenes de la película de Alejandro González Iñárritu Biutiful (2011); sobre todo aquellas que me ayuden a poner en relación este film con el fenómeno del denominado World Cinema y con las teorías de lo vernacular preconizadas por la pensadora alemana, muerta este mismo año, Miriam Bratu Hansen².

PALABRAS CLAVE: Biutiful - World Cinema - Vernacular - Alejandro González Iñárritu

\footnotetext{
${ }^{1}$ Autor Correspondiente:

Lorenzo J. Torres-Hortelano: Universidad Rey Juan Carlos. Facultad de Ciencias de la Comunicación. Grupo de Investigación INFOCENT. Madrid (España)

Correo: lorenzojavier.torres. hortelano@uric.es

${ }^{2}$ Hansen (1949-2011) murió también de cáncer, como lo hace Uxbal, el protagonista de la película; asimismo fue emigrante (de Alemania a EEUU), como el padre republicano de Uxbal; y fue especialista en Walter Benjamin, otro emigrante desterritorializado que vino a morir cerca de una frontera, próxima al Pirineo Navarro donde sucede el sueño de Uxbal, en Portbou (frontera franco-española), más o menos en la misma época que el padre de Uxbal, el cual, como Benjamin, huía del fascismo. Hansen recibió The Ferdinand Schevill Distinguished Service Professor in the Humanities; fue profesora en los Departments of Cinema \& Media Studies and English; fundadora del Film Studies Center; y miembro del claustro de profesores de la University of Chicago Press. Hansen cambió los límites de los estudios fílmicos integrando el análisis del modernismo y las formas vernaculares en línea con los escritos de Siegfried Kracauer, Walter Benjamin y otros pensadores de la Escuela de Frankfurt.
} 


\section{ABOUT THE VERNACULAR AND WORLD CINEMA IN BIUTIFUL}

\section{ABSTRACT}

My aim in this paper is to textually analyse some images from Alejandro González Iñárritu's Biutiful (2011); especially those which will help me to relate this film to the phenomenon of the so-called World Cinema and the vernacular theories advocated by the German thinker Miriam Bratu Hansen, who died this year.

KEY WORDS: Biutiful - World Cinema - Vernacular - Alejandro González Iñárritu

\section{INTRODUCCION}

He elegido Biutiful como objeto de estudio porque es un magnífico ejemplo de las contradicciones que se perciben entre la recepción del público de las películas pertenecientes a este macrogénero globalizador y las diferentes identidades culturales que, por su parte, se deducen de las peculiaridades vernaculares de cada una de las culturas de las que surge el World Cinema.

Mi hipótesis de trabajo es que Alejandro González Iñárritu, en Biutiful, lejos de haber perdido pulso narrativo, como se le viene criticando ${ }^{3}$, propone de manera honesta y decidida una reflexión sobre las contradicciones que surgen de este choque señalado; pero intentando que el propio texto sea campo de juego para esas contradicciones, es decir, llevando esa reflexión a la propia letra del texto. De hecho, como intentaré demostrar, creo que su puesta en escena y su capacidad de estructurar un relato está más concentrada y conseguida en Biutiful que en cualquiera de sus obras anteriores.

\section{METODOLOGÍA}

Se ha empleado el método lógico-abstracto que nos ha permitido, de forma general, establecer mediante la comparación las analogías y diferencias existentes entre los distintos fenómenos u objetos y sus propiedades; en otras palabras, establecer una comparación a través de las particularidades extraídas del análisis textual de algunos fragmentos e imágenes de la película de González Iñárritu, con las teorías de la pensadora Miriam Bratu Hansen.

\footnotetext{
${ }^{3}$ Más abajo haré referencia a un artículo en este sentido de Daniel Krauze, Biutiful, o los límites del azar. disponible en: www.letraslibres.com/index.php?art=15211\&rev=2:, enero de 2011 (Consultado el 03/04/2011).
} 


\section{ANÁLISIS Y DISCUSIÓN}

\section{1 ¿Qué es el World Cinema?}

El término World Cinema se suele utilizar principalmente en el ámbito anglosajón para referirse a las películas y cinematografías de países de habla no inglesa. En este sentido, es un término intercambiable con el de foreign film o película extranjera. De ahí, por extensión, se ha convertido en nombre para todo un macrogénero, dado que abarcaría películas dramáticas, de comedia, de cine de autor, etc. De entrada, pues, puede asumirse que el cine iberoamericano se encuadra en esta denominación, por supuesto, con todos los matices que se quiera, los cuales van a ir apareciendo en mi análisis. Más allá de esta localización geográfica, que parece hacer referencia implícita al cine del resto del mundo (no anglosajón), tenemos que en el término World Cinema se trasluce una oficiosa referencia a películas con cierto valor artístico en oposición al cine comercial de Hollywood, abarcando, pues, denominaciones del tipo cine independiente o Art House, representados, por ejemplo, por Won Kar-wai, Takeshi Kitano o Lars Von Trier y, en nuestro ámbito, por Pedro Almodóvar, Juan José Campanella o Alejandro González I ñárritu.

Esta traza autoral de Iñárritu ya puede rastrearse en los carteles de sus cuatro largometrajes, en los que domina el negro para el fondo y el rojo y el blanco para los títulos.

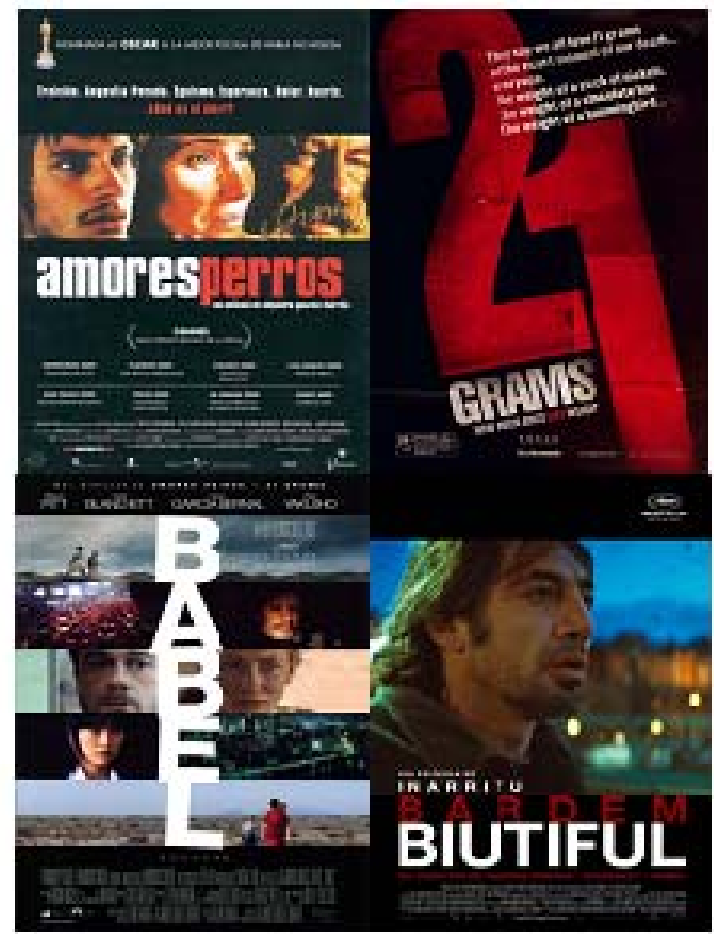

Figura1. Carteles de los filmes de González I ñárritu.

Esta apreciación, que tiene que ver con la recepción por parte del público, se manifiesta también en la esfera industrial desde el momento en el que las películas de estos directores -y subrayo directores, puesto que en este ámbito se les suele 
considerar autores-, filmadas en habla no inglesa y exhibidas en versión original, a menudo se las clasifica en la sección de películas de DVD de las grandes superficies así como en todo tipo de listas, como Art House Films, cine independiente, de autor, etc.; por ello mismo, su distribución suele ser muy limitada en salas (en los circuitos de versión original y con subtítulos) y más común en la ventana del DVD. La combinación de todos estos factores suele llevar a la conclusión de que nos encontramos ante un producto de prestigio o de alta calidad que puede, por tanto, amedrentar a espectadores poco sofisticados, pese a que, de entrada, son películas con vocación de atravesar fronteras y culturas, ayudando, pues, a dar forma un espectador global e intercultural. Sin embargo, históricamente, la primera película considerada como integrante de este World Cinema y que triunfó en el Box Office norteamericano fue Hero (Zhang Yimou, 2004) ${ }^{4}$, precisamente, un relato de época que refleja las espesas fronteras y la desconfianza entre el mundo de los poderosos y la plebe medieval china; es decir, portadora de un sentido radicalmente contrario a la globalización que puede deducirse de este tipo de cine 0 , al menos, proponiendo una reflexión sobre ello, como podemos comprobar en las secuencias dedicadas a las conversaciones entre el protagonista de Hero, Sin Nombre, y el soberano de Qin.

Iñárritu no es ajeno a toda esta problemática que, además, tiene que ver con la conservación y difusión de otro tipo de cine diferente al hegemónico hollywoodense. De hecho, el director mexicano forma parte del Consejo de Directores, Filmmakers Board, de la World Cinema Foundation ${ }^{5}$, que es una organización sin ánimo de lucro, no gubernamental, dedicada a la preservación y restauración del cine más desconocido y, por ello, más indefenso, del mundo. Se fundó en 2007, a semejanza de otra fundación norteamericana, la Film Foundation5, en cuyo arranque también participó Martin Scorsese y cuyo máximo objetivo es, asimismo, preservar películas no sólo norteamericanas ${ }^{6}$.

\subsection{Alta, media y baja cultura}

De aquí surge otro tema que atañe al World Cinema: un debate entre la alta y la baja cultura que es también un tema recurrente en la cultura de la globalización -y de ahí surge parte del éxito de la película Hero-; teniendo en cuenta que es una reflexión que surge ya en los orígenes de la Modernidad, por ejemplo, en la obra de Walter

\footnotetext{
4 Información disponible en: www. boxofficemojo.com/weekend/chart/?yr=2004\&wknd=35\&p=.htm. (Consultado el 01/04/2011), semana del 27-29 de agosto de 2004. Es significativo que esta película consiga este resultado en taquilla la última semana de agosto, cuando la asistencia a los cines es de la más altas del año, a lo que ayuda, sin duda, el que uno de los géneros que tradicionalmente tiene más éxito entre los norteamericanos sea el de acción con dosis de lucha, artes marciales (Wuxia), etc. Los matices son aquí también importantes, pues, hasta la fecha, fue la película más cara de cine chino (31 millones de dólares) y tuvo el apadrinamiento de Tarantino en su estreno en EEUU -por cierto, otro autor que interesa a la hora de hablar del World Cinema. Otra película similar en éxito y género; pero que no se corresponde exactamente con el World Cinema, pues EEU participa en su producción, y cuyo director es de formación norteamericana, es Tigre y dragónl Wo hu cang long (Ang Lee, 2000).

${ }^{5}$ Consultado el 04/04/2011, Disponible en:

www. film-foundation.org/common/11004/default.cfm?clientI D=11004\&thispage=homepage.

6 Por ejemplo, el 30 de octubre de 2010 presentaron la restauración de La dolce vita (Federico Fellini, 1960) en Roma.
} 
Benjamin, sobre todo cuando habla de la dialéctica entre el concepto de aura y el arte en la época de su reproductibilidad técnica -tendré tiempo de volver sobre ello en el análisis de secuencias concretas de Biutiful.

Un autor que ha nombrado explícitamente este debate es Umberto Eco en Apocalípticos e integrados. Eco, por ejemplo, califica al pensador norteamericano Dwight MacDonald de apocalíptico en el sentido de que éste plantea un enfoque pesimista acerca de la influencia de los medios globales de comunicación. Dwight MacDonald teorizó en su ensayo previo, Masscult and Midcult ${ }^{7}$, sobre la alta, media y baja cultura. En resumen, para MacDonald la alta cultura fueron Joyce, Proust 0 Picasso, "mientras que la masscult se manifestaba en toda la pacotilla hollywoodiana, desde las tapas del Saturday Evening Post y el rock" (Eco, 2010). Esto ya es interesante para mi análisis, pues sitúa al cine hollywoodense en la baja cultura.

MacDonald señala un tercer ámbito, el de la cultura media (Midcult), que estaría representado por Somerset Maugham, el último Ernest Hemingway o Thorton Wilder (Eco, 2010); es decir, autores de mucho éxito popular, pero capaces de ofrecer una obra personal y de calidad. Lo curioso es que la dicotomía propuesta por Eco se salta este nivel intermedio en el que, precisamente, creo se mueve una película como Biutiful.

Aquí será pertinente introducir las reflexiones de Hansen, las cuales nos servirán para analizar un ámbito con el que suele entrar en conflicto la globalización, el de lo vernacular, y de cuyo campo de batalla Biutiful es un ejemplo extraordinario. Muchas de sus imágenes son cristalizaciones de esta problemática, ya sea en ejemplos cotidianos de baja y media cultura;

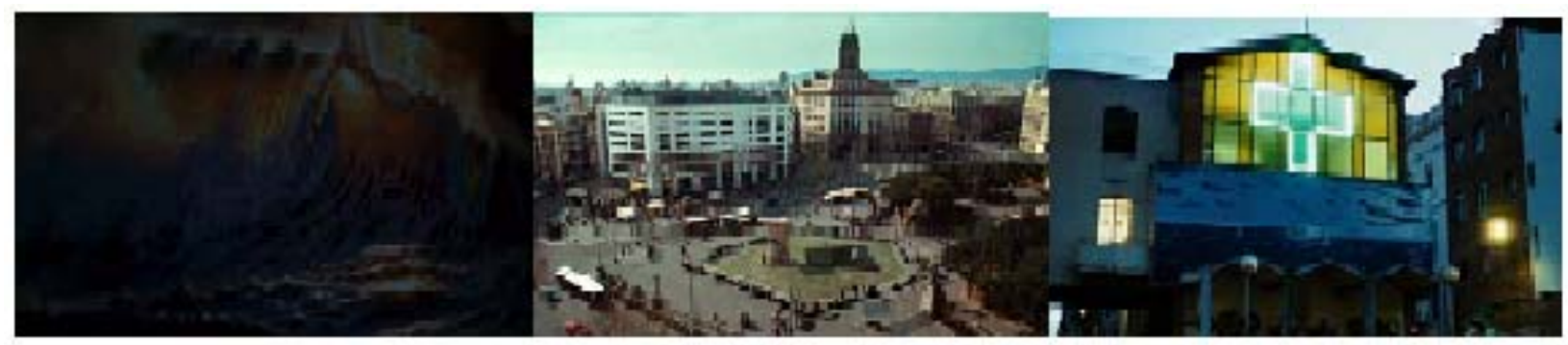

Figura 2. Escenarios del filme que reflejan esa problemática ${ }^{8}$.

\footnotetext{
${ }^{7}$ Recogido y traducido en español en VV. AA. (1969): La industria de la cultura. Madrid: Alberto Corazón

${ }^{8}$ Plaza de Cataluña. Constituye el punto de unión entre el núcleo viejo de la ciudad y el ensanche; por lo que de nuevo vemos el deseo de Iñárritu de crear puentes entre dos mundos, los de Uxbal; pero también los del World Cinema y lo vernacular. En este sentido, el monumento que se ve en el centro está dedicado a Macià de Subirachs, figura clave del republicanismo e independentismo catalán. Lo más interesante, sin embargo, es que este monumento tapa con su sombra a una escultura de Josep Clarà titulada La Diosa y que entronca con el tema de la mujer avasalladora que aparece en Biutiful, pese a que esta escultura en concreto es de un estilo muy clásico y representa a la Diosa comedida; pero muy seductora.
} 


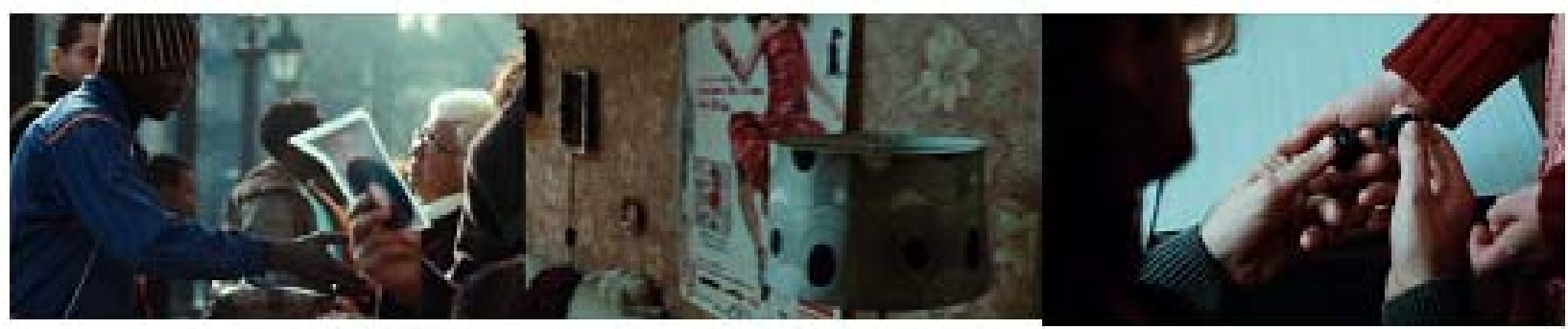

Figura 3. Imágenes del filme que reflejan esa problemática.

O a través de estilizaciones de la realidad en las que, junto a la imagen, la música de Gustavo Santaolalla acompaña en la mejor tradición del melodrama -género que analizo más abajo-, recogiendo el estilo de artistas de la considerada alta cultura, como David Lynch ${ }^{9}$, Robert Doisneau ${ }^{10}$ o René Magritte ${ }^{11}$, todo ellos, además, creadores que manipulan el azar, como Iñárritu.
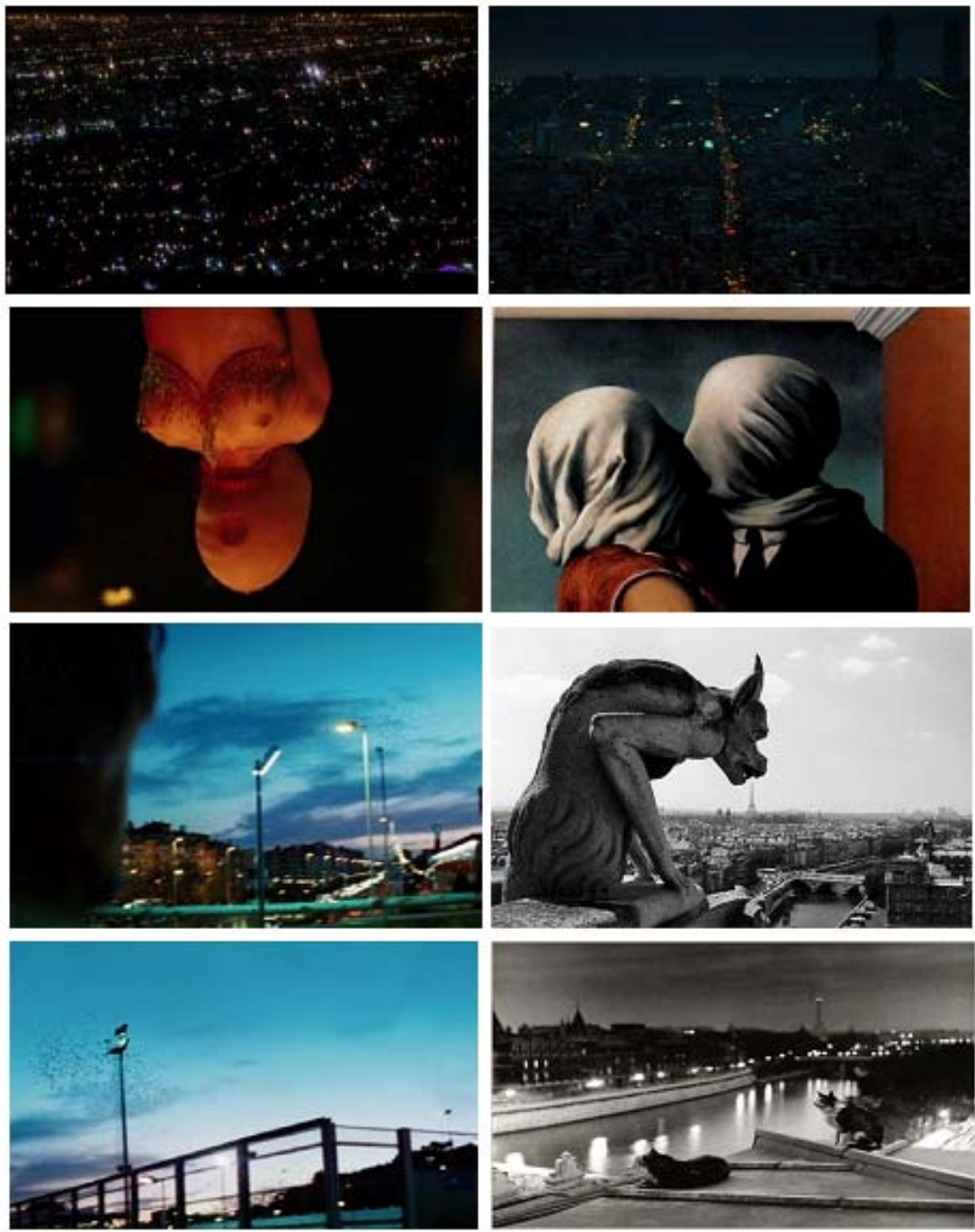

Figura 4. Imágenes del filme y referentes que reflejan esa problemática.

\footnotetext{
${ }^{9}$ Lynch, David (2001). Mullholland Drive.

${ }^{10}$ Doisneau, Robert (1949). Gargouille de Notre-Dame y (1954): París, los gatos, la noche.

${ }^{11}$ Magritte, René (1927-28). Los amantes.
} 
La labilidad diacrónica de las fronteras entre estos tres niveles es patente, por ello, Eco señala como "la distinción entre dos (o tres) culturas se vuelve neta sólo cuando las vanguardias históricas se proponen como objetivo provocar al burgués, y entonces eligen como valor la no-legibilidad, o el rechazo de la representación" (Eco, 2010) ${ }^{12}$. ¿Podemos rastrear esa energía vanguardista en el cine de Iñárritu 0 , como hemos señalado más arriba, más bien tiene razón la crítica que considera que el cine de Iñárritu no deja de ser una pose que señalaría hacia otro aspecto del World Cinema, impregnado de relativismo cultural, que nos mostraría un cine hecho para festivales de prestigio $^{13}$, sin personalidad, mezcla inconexa de elementos vernaculares proveniente de diferentes culturas -y ahí Babel sería presa fácil?:

Las cintas de González Iñárritu no han mejorado con el tiempo. Sí: sus habilidades como director se han afinado: 'Biutiful' es más elegante que 'Amores perros'. Aun así, los productos finales se sienten cada vez más difusos. Después del éxito innegable de su primera cinta (que sigue siendo una obra maestra y un hito en el cine mexicano y mundial), la historia de '21 gramos' adoleció de una edición inexplicablemente desordenada y un exceso de cadáveres, hasta para los estándares del cine de González Iñárritu. Luego vino 'Babel' que, a pesar de haber recogido decenas de premios y nominaciones en Estados Unidos, dejaba la impresión de cierta arbitrariedad. La obra de González Iñárritu parecía alejarse de sus virtudes iniciales: la elocuencia de los perros como símbolo de las feroces relaciones chilangas, la concreción de narrar una historia en un solo lugar. En otras palabras, el éxito de 'Amores perros' se debía, en gran medida, al hallazgo de la simbología perfecta para contar una épica concisa, propia de una urbe única: la ciudad de México. '21 gramos' perdió la fuerza de esa concentración simbólica y quizás por eso resultó vaga: una cinta que bien podría haberse situado en cualquier ciudad del mundo. 'Babel' acentuó esas fallas: una película cuya 'globalidad' parecía un ejercicio forzado; la idea de hablar de muchas cosas sofocaba esa necesidad primigenia del cine: exponer una idea y exponerla bien (Krauze, 2011, p. 64) ${ }^{14}$.

La amplitud de la cita nos da cuenta del sentido tutor que suele acompañar a la crítica generalizada sobre el cine de Iñárritu. En mi caso, como he apuntado más arriba, me sitúo en un lugar radicalmente distinto a este sentido tutor, pues creo que esas aptitudes perfeccionadas de Iñárritu no le llevan al automanierismo hacia el que parece señalar Daniel Krauze; todo lo contrario, si pensamos que en Biutiful la estructura narrativa ha sufrido un proceso de destilación. Este proceso, por cierto, sólo puede provenir de un suceso similar a los azarosos que salpican sus relatos fílmicos: el hecho de haber dejado de coescribir sus guiones con su colaborador habitual, Guillermo Arriaga. Digo azaroso porque, hasta donde he llegado, no parece haber una explicación oficial al respecto. Pero, disintiendo de nuevo de lo que afirma Krauze -"En

\footnotetext{
${ }^{12}$ Una elaboración más profunda de esta idea se encuentra en González-Requena, J esús (2008).

${ }^{13}$ Todas las películas que ha restaurado la World Cinema Foundation se han estrenado en el Festival de Cannes, catorce en total si contamos la edición de 2011.

${ }^{14}$ La negrita es nuestra.
} 
Biutiful, a fin de cuentas, no hay una sola cosa que le ocurra a Uxbal que no esté supeditada a la suerte" (Krauze, 2011)-, pienso que en un buen filme nada ocurre al azar, ni en cómo se cuenta ni en lo que se cuenta. Por ejemplo, quizá para entender ese suceso al que hacíamos referencia, tendríamos que tener en cuenta algunos aspectos (vernaculares) de las biografías de los dos protagonistas: Arriaga afirmaba en una entrevista: "Puede ser que yo haya salido de la calle, pero la calle no ha salido

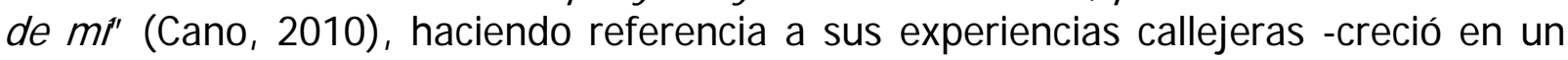
barrio de clase media-baja muy violento, frente a la posición más acomodada de Iñárritu- que, por ejemplo, le hicieron perder el olfato como consecuencia de una brutal pelea a las 13 años. Por todo ello afirma que es más un cazador que un escritor (Cano, 2010) -como Miguel Delibes-.

Cuando Krauze -y las críticas del mismo talante- habla negativamente de globalidad sin más argumentos en su análisis de Biutiful, pone por delante un prejuicio que le desautoriza. La globalización, y su reverso milenario, la lucha de los oprimidos contra los poderosos, ha ofrecido desde los orígenes del cine maravillosas obras como Intolerancia/Love's Struggle Through the Ages (David Wark Griffith, 1916). Lo que intento, pues creo que el mismo Iñárritu lo elabora, es reflexionar sobre esa globalización a partir de Iñárritu, sin valorarla desde el principio.

\subsection{Lo vernacular}

Para Hansen, a partir de la Modernidad, se transforman las condiciones en la que se produce, se transmite y se consume el arte; lo que acaba creando diferentes concepciones en el público entre el high y el low art - que nos recuerda a Eco y MacDonald. Hansen, ayudándose de Benjamin, propone pensar, en relación a esa clasificación cultural, en una nueva economía sensorial de la percepción (Hansen, 1999, p. 59) (frente al esteticismo que denunciara Benjamin (1973)), puesto que:

the shift to mass consumption entailed processes of real destruction and loss, there also emerged new modes of organizing vision and sensory perception, a new relationship with 'things,' different forms of mimetic experience and expression, of affectivity, temporality, and reflexivity, a changing fabric of everyday life, sociability, and leisure15 (Hansen, 1999, p. 60) ${ }^{15}$.

Es decir, que no nos podemos quedar sólo en lo que McDonald, Eco -y Krauze en otro ámbito- clasifican de manera un tanto desapegada: como señala Hansen a través de Benjamin, se dan ahí unos procesos que afectan al ser humano. Y por aquí ya podemos considerar el texto Biutiful de otra manera, pues por encima de su mayor o menor acercamiento a cierta moda del World Cinema o de fenómenos como la

\footnotetext{
15 "El paso al consumo masivo supuso procesos de destrucción y la pérdida real, también surgieron nuevas formas de organización de la percepción sensorial y la visión, una nueva relación con las 'cosas', diferentes formas de experiencia mimética y de expresión, de afectividad, temporalidad y reflexividad, un tejido cambiante de la vida cotidiana, la sociabilidad y de ocio". Todas la traducciones de los textos de Hansen son mías.
} 
globalización, hay un ser personaje, Uxbal, con el que todos los espectadores se identifican, que, por encima de todo, sufre y que ve cómo, al tiempo que cada segundo de su vida se le escapa, su forma de mirar al mundo cambia. Aquí cobran sentido dos de los aspectos más sobresalientes del film: el protagonismo (¿excesivo?) de Javier Bardem y la especial visualidad (¿New Age, World Cinema?) del film.

Desde esta perspectiva, Hansen propone un análisis de la estética de la Modernidad denominando como vernacular a lo que Eco o MacDonald llamarían baja cultura, evitando, de todas formas, el término cultura popular - por estar ideologizado-, porque lo vernacular combina la dimensión de lo cotidiano con connotaciones del discurso, la lengua y el dialecto, con lo promiscuo, la capacidad de traducción, etc. Hansen lo centra mucho en el (norte)americanismo y en el cine clásico; pero ambos aspectos nos atañen a Biutiful: protagonista y director están oscarizados, por lo que su apuesta no deja de ser una toma de postura ante aquello de lo que, de otro lado, ya forman parte (Hansen, 1999, p. 60).

Hansen critica que se pueda considerar al Cine clásico de Hollywood como anticuado, hegemónico, tergiversador, etc., frente al cine modernista ${ }^{16}$ que vendría después; pero no solo por superar una argumentación baja/alta cultura; sino porque ese modelo de representación supuso la primera manifestación global vernacular. Su éxito no vendría solo por su carácter hegemónico e industrial, sino porque

It played a key role in mediating competing cultural discourses on modernity and modernization, because it articulated, multiplied, and globalized a particular historical experience (Hansen, 1999, p. 68). ${ }^{17}$

De nuevo, creo que algo de esa experiencia histórica que nos ha tocado vivir a través de la globalización es algo que está en la letra misma del texto Iñárritu (no sólo en Biutiful). El cine clásico de Hollywood -y Biutiful- se consumen en sociedades concretas, con desarrollos y contextos muy diferentes entre sí; pero no por ello el único ni más importante efecto es el de erosionar las diferencias, sino que, históricamente, supuso un desafío a elementos cultures establecidos en todos los ámbitos: sexuales, identitarios, intergeneracionales, etc., y manifestaciones de libertad en general. En este sentido, el cinematógrafo no era solo uno más de los síntomas de la Modernidad, sino que se erigió en todo un horizonte cultural en el cual los efectos traumáticos de la Modernidad se reflejaban convulsamente. Este horizonte convulso, necesariamente, debía dar paso a cierta reflexión sobre el medio, y ahí podemos ver los cambios hacia el manierismo y el postclasicismo ${ }^{18}$, así como a los nuevos cines a

\footnotetext{
${ }^{16}$ En este sentido, recomendamos la lectura de la obra de González Requena (2006): Clásico, manierista, postclásico. Los modos del relato en el cine de Hollywood. En ella, partiendo de otras argumentaciones, se llega a las mismas conclusiones en este sentido, correspondiendo el concepto de Hansen de moderno al manierista y postclásico de González Requena.

17 Desempeñó un papel clave en la mediación de la competencia entre discursos culturales de la Modernidad y la modernización, porque articuló, multiplicó y globalizó una experiencia histórica particular.

${ }^{18}$ Véase la nota 13.
} 
partir de los años 60 (Hansen, 1999, p. 79). De nuevo, Biutiful creo que se coloca en el centro de ese movimiento reflexivo que se inició en Hollywood, ya de manera globalizada, y que el film de Iñárritu lleva hasta al límite:

Hollywood did not just circulate images and sounds; it produced and globalized a new sensorium; it constituted, or tried to constitute, new subjectivities and subjects. The mass appeal of these films resided as much in their ability to engage viewers at the narrative- cognitive level or in their providing models of identification for being modern as it did in the register of what Benjamin troped as the 'optical unconscious'. (Hansen, 1999, p. 71). ${ }^{19}$

Sin lugar a dudas, Iñárritu quiere poner en escena este "inconsciente óptico" en Biutiful, en la propia narrativa del texto y por eso el film arranca y termina con la misma secuencia, pausando de esta manera el tiempo, es decir, convirtiéndolo en un tiempo onírico y resultando ser la película así un gigantesco flashback (que no es lo mismo que los saltos temporales y narrativos que resultaban de su colaboración con Arriaga); asimismo, narrativamente, este inconsciente óptico está en la letra del texto si tenemos en cuenta la capacidad de Uxbal de hablar con los muertos y de cómo es testigos de cómo sus almas salen del cuerpo físico; por último, se manifiesta también en la puesta en escena, por ejemplo, en esas manchas que van apareciendo y transformándose en el techo del dormitorio de Uxbal, y por la diferente manera en las que las vamos mirando a través de su mirada paulatinamente moribunda.

Este inconsciente óptico nos lleva, de la mano de Iñárritu, a otro tema crucial de la Modernidad: la desaparición de Dios; por ejemplo, cuando al principio del film, sobre esas manchas a las que mira Uxbal, aparece dibujada en el techo una sombría cruz. Cuando más avanzada la película desaparece esta cruz, sólo quedarán las manchas de humedad citadas y unas mariposas negras que irán creciendo en número a lo largo del relato y que instaura un punto de vista (el de Uxbal) que será, precisamente, el último que compartamos con él antes de su muerte. En este sentido, la desaparición de la cruz apunta hacia ese otro lado de la Modernidad que todavía no ha sido superado: tras la muerte de Dios, cabe la posibilidad de creer en cualquier cosa (hablar con los muertos) o persona (la médium, interpretada por Blanca Portillo).

\footnotetext{
${ }^{19}$ Hollywood no hizo circular sólo imágenes y sonidos; sino que produjo y globalizó un sensorio común nuevo; constituyó, o trató de constituir, nuevas subjetividades y sujetos. El atractivo para las masas de estas películas residía tanto en su capacidad para atraer a los espectadores en el nivel narrativocognitivo o en sus modelos provistos de identificación para ser moderno como lo hizo en el registro de lo que Benjamin denominó como el 'inconsciente óptico'.
} 


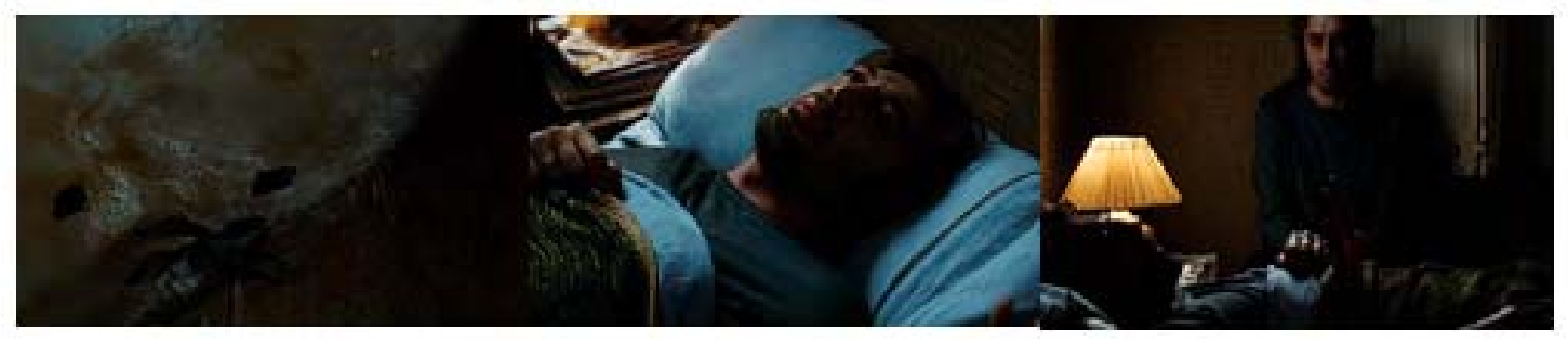

Figura 5.Uxbal contemplando las manchas, ya sin cruz ninguna.

La prueba evidente de que Iñárritu recoge íntimamente esta dialéctica que he intentado bosquejar entre el World Cinema y lo vernacular, a través de una ciudad cosmopolita y muy identitaria o nacionalista al mismo tiempo como es Barcelona, la encuentro en el propio título del film: Biutiful. En un momento dado del relato, la hija del protagonista está realizando unas tareas del colegio y le muestra a su padre esa palabra inglesa para saber si está bien escrita: una palabra global que, aunque escrita erróneamente, nos habla de la belleza del mundo -si queremos verla- y de la dificultad de alcanzarla, de su aprendizaje; al tiempo que nos recuerda cómo lo vernacular - en el sentido de cómo cada sociedad adapta estos textos globalespersiste en todo momento. Más avanzado el relato, esa palabra se relaciona con los Pirineos, como lugar primigenio e imaginario donde poder formar una familia (como parece dibujada) y ser feliz fuera de la Barcelona lúgubre.

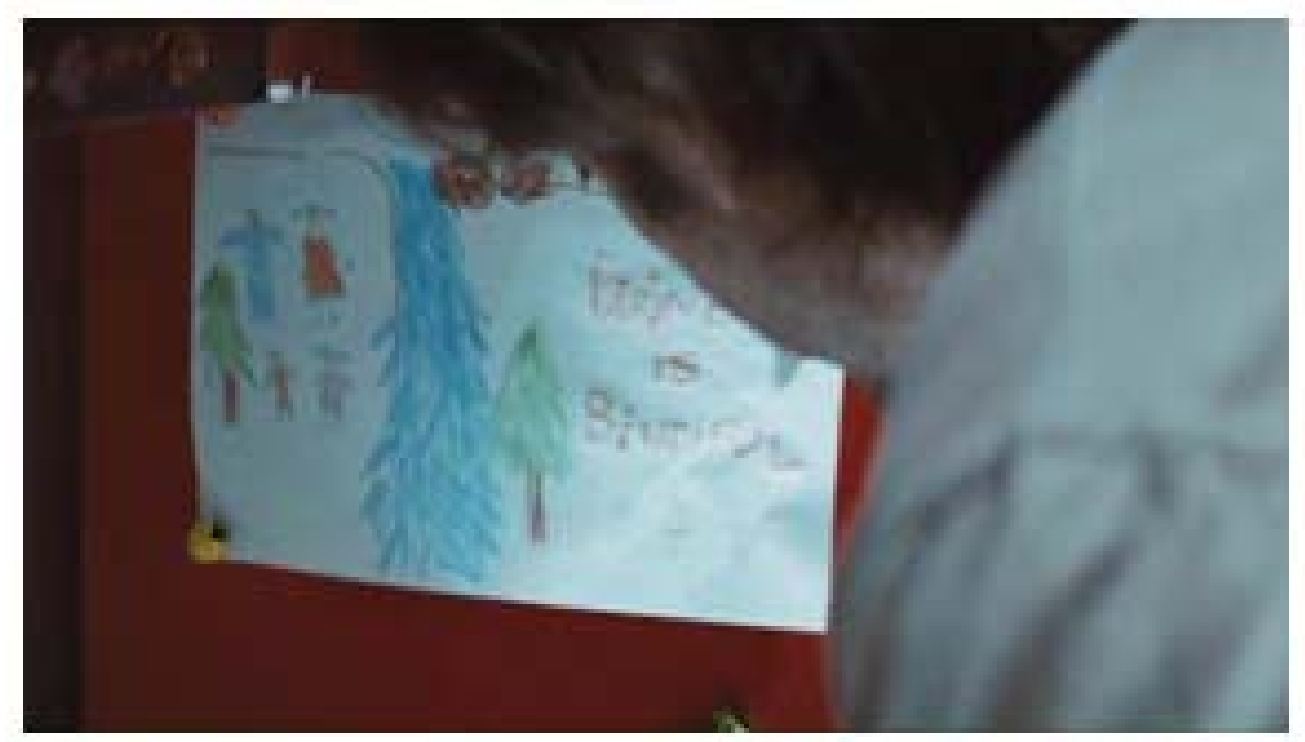

Figura 6. Pirineos is Biutiful.

\section{4 Esquema narrativo}

El relato arranca y termina en el mismo punto: Uxbal y su hija Ana hablan acerca de un anillo tumbados en la cama de una habitación oscura. Lo que ocurre en medio del metraje es, pues, un gran flashback. Encabalgado al diálogo de esta secuencia de arranque entre padre e hija, asistimos a una secuencia onírica: un bosque nevado, una lechuza muerta, Uxbal y otro hombre más joven que él. Solo al final del relato 
sabremos que este hombre es su padre, al que no conoció, pues se exilió a México por motivos políticos (era republicano), donde éste murió al poco tiempo.

La historia en sí -el amplio flashback- empieza en un hospital: Uxbal, un padre desesperado e infortunado, separado con dos hijos pequeños, pasa una revisión médica: le diagnostican un cáncer de próstata que sólo le permitirá vivir unos pocos meses más.

Para sacar a sus hijos adelante, dirige con guante blanco tanto el trapicheo de drogas de su barrio barcelonés, el Raval, como la trata ilegal de inmigrantes. A medida que avance la historia, Uxbal se irá implicando cada vez más en las vidas de los camellos y sus familias, en la de los inmigrantes chinos y africanos, y con su propia familia desestructurada.

Además, Uxbal, a modo de médium, tiene la capacidad de hablar con los muertos, es decir, de poner en contacto a dos mundos separados, como pone en contacto a la policía con el submundo de la droga y a los inmigrantes ilegales con los capataces de las obras. En este último caso, ayudado por su hermano, que se acuesta con su mujer, Marambra, quien a su vez sufre un trastorno bipolar que le impide llevar una vida normal: trastorno, pues, que resuena en la posición de médium de Uxbal.

Éste, antes de morir, quiere poner en orden su vida lanzándose a una carrera contrarreloj en la que necesita perdonar: a su hijo por mearse en la cama, a su esposa (a la cual deja volver a casa, resultando un intento fallido); a su hermano (que le ayuda constantemente, pero que le traiciona con Marambra), y a sí mismo (por su implicación en la muerte de los inmigrantes chinos o la deportación del inmigrante africano a través de la esposa de éste).

Finalmente, antes de morir, conseguirá ponerse en paz consigo mismo y donará a sus hijos un regalo simbólico, más allá del dinero que conseguirá reunir a marchas forzadas: la sencillez de unas piedras negras (protectoras). Estas piedras encierran una enseñanza: lo que vale la pena en la vida está más allá de lo imaginario - la escena de la médium en la que ésta dona a su vez las piedras en primer lugar a Uxbal se encuentra en el centro geométrico del film, lo que la dota de una gran carga simbólica.

\subsection{Antecedentes}

Biutiful, como he señalado más arriba, es el primer largometraje que González Iñárritu realiza sin contar con Guillermo Arriaga, su guionista habitual -aunque la semilla de este proyecto se plantó en 2006, año en el que rompió con Arriaga. El propio director empezó a escribir el guion y, posteriormente, le asistieron los argentinos Armando Bó y Nicolás Giacobone. Si 21 gramos (2003), Amores Perros (2005) y Babel (2006), son muestras de narraciones fragmentadas, quizá por esta ausencia esencial, el relato de Biutiful es lineal, exceptuando, como hemos señalado más arriba, que la mayor parte de la película es un gran flashback: por ello mismo, dado que se trata de la única violentación narrativa, se debe tener especialmente en cuenta, pues quizá ahí se 
encuentra la clave de la figura de Uxbal: una pieza de engranaje en un mundo globalizado que no acaba de funcionar.

Precisamente, una de las máximas virtudes de Iñárritu es su capacidad de haber sabido conjugar toda una serie de claves narrativas y estéticas que parten de lo vernacular para ofrecer una obra que va dirigida a un público global, señalando las contradicciones de esta globalización y sin caer en la demagogia. De hecho, puedo imaginar que cuando Iñárritu llegó por primera vez a Barcelona en 1981, en plena juventud y malviviendo, seguramente experimentó una contradicción brutal al comprobar que vivía en mundo global, al tiempo que se encontraba con un nacionalismo cerrado, manifestación extrema de lo vernacular.
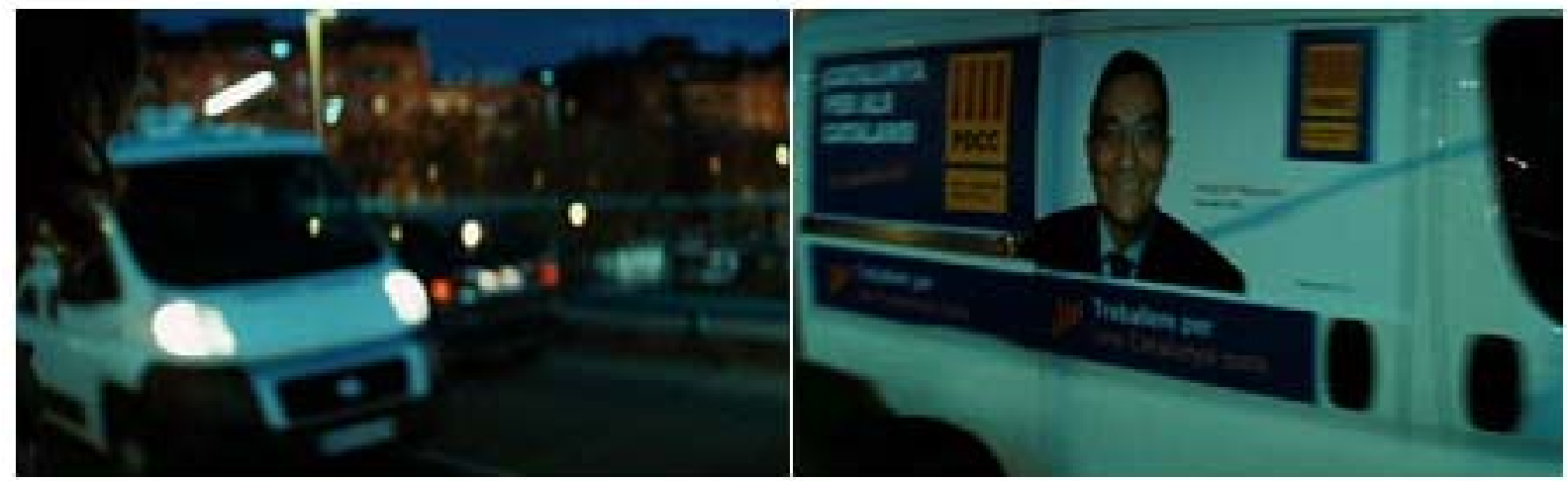

Figura 7.Vernacular frente a mundo global.

Por ello, quizá, al mismo tiempo, esta característica tan afín al World Cinema suele convertirse a menudo en diana de las mayores críticas contra el cine de Iñárritu, pues su obra parecería caer en cierto relativismo cultural. Esta dialéctica no deja de mostrar las fallas y complejidades del fenómeno por excelencia del siglo XXI: la globalización, empezando por la dependencia de los nacionalismos que todavía se percibe en el mundo global de la cultura -y que, no lo olvidemos, está en la raíz de lo peor de la historia reciente europea.

\subsection{Melodrama de autor}

Sin embargo, la clave escogida es algo tan afín a lo latino como el melodrama; eso sí, concretamente se encuadra en el melodrama de autor, del cual este director mexicano es todo un maestro. Y con derivaciones hacia el cine social; pero cargado de poesía. Esta elección, ya presente en Babel, por ejemplo, suele ser también causa de exacerbadas críticas -a Iñárritu y al audiovisual iberoamericano en general-; sin embargo, como ya he argumentado en otro lugar20, es absurdo seguir considerando a las películas que conforman este género de manera peyorativa, más cuando grandes creadores mundiales contemporáneos transitan por éste de manera exitosa: Won Karwai, James Cameron, Steven Spielberg, M. Night Shyamalan, Anthony Minghella, Takeshi Kitano o Roberto Benigni, cuyos filmes han tenido un enorme éxito mundial

\footnotetext{
${ }^{20}$ Véase Torres-Hortelano, Lorenzo J. (en prensa).
} 
de público y crítica y son ya parte del imaginario colectivo mundial -o del inconsciente óptico benjaminiano.

Empieza a hablarse de melodrama en el siglo XVII, sobre todo en el ámbito del teatro y la ópera, de los que surgirán obras marcadas por personajes muy definidos en la vena sentimental, subrayada por una música de similar carga emotiva. Pero suele olvidarse un aspecto importante en este sentido: que todas ellas eran manifestaciones artísticas de eminente carácter popular; empezando por la ópera que, históricamente devino más elitista -este hecho marca el camino para yuxtaponer el término "melodrama" al de "autor".

Posteriormente, por extensión, el término "melodrama" se ha hecho común para referirse a todo tipo de textos dominados por aspectos patéticos más o menos lacrimógenos, para hacer surgir toda una serie de emociones de las que, quizá, en nuestra vida diaria, nos sentiríamos avergonzados si tuviéramos que expresarlas en público. Además, habitualmente, el público objetivo del melodrama era mayoritariamente femenino. Pero, a pesar de éste carácter exaltado de las emociones, se sobreentiende que las películas de género melodramático tienden a ser realistas.

Si entre los maestros clásicos del género se puede nombrar a Douglas Sirk, Kenji Mizoguchi, Frank Borzage, Satyajit Ray, Max Ophüls o Vincent Minnelli y, en el siglo $X X I$, puede establecerse que algunos de los mejores directores que a menudo bucean en este género son iberoamericanos: Isabel Coixet, Juan José Campanella, Pedro Almodóvar o el mismo Iñárritu.

Como ha establecido Jesús González Requena (2007, pp. 281-283), el melodrama empezaba a diferenciarse, como escritura fílmica de la clásica, por ejemplo, a través de la sabia utilización de la imagen kitsch (baja cultura) -tan afín a Almodóvar o Bigas Luna; pero también a Iñárritu. Con este tipo de imagen empezaba a aparecer una distancia entre el espectador y su objeto de observación (a modo de estructura voyeurística), participando en el sufrimiento de la heroína; pero no del todo. El héroe melodramático pierde su objeto de deseo; pero no está a la altura a la hora de recuperarlo: esto le causa una herida a modo de duelo y, sobre todo, hundiéndole en una especie de melancolía - nuestro héroe, Uxbal, está situado ahí; pero logra, al menos, hacer una donación a sus hijos y comprometerse con su entorno, lo cual le acerca al héroe clásico. Por ello la audiencia del melodrama atiende a través de una mirada que ya no es del todo clásica, sino como la denomina González Requena, manierista.

Hasta aquí una definición somera del melodrama. Entonces ¿es apropiado yuxtaponer ese concepto al de autor? Anticipándome a la objeción, diré que esta contradicción es sólo aparente. En primer lugar, es una pregunta que surge inmediatamente al experimentar el cine de Iñárritu: hay melodrama y hay estilemas de autor. Como es sabido, el cine de autor escapa, por definición, a cualquier intento de categorizar sus textos, pues se quiere expresión individual de un director o un autor cuya firma dicta la personalidad, apariencia y significado de cada film. 
En un breve recorrido histórico se comprueba que no es hasta los años 70 cuando en la teoría fílmica se empiezan a asentar de manera definitiva las características de cada género tal como los conocemos hoy en día, puesto que hasta este momento su papel era meramente industrial. Es precisamente en la década anterior, la de los 60, cuando un grupo de críticos franceses, a través de Cahiers du Cinéma, empiezan a hablar del papel del autor (auteur) como alguien que se expresa a sí mismo de una forma única e individual, haciendo prevalecer los estilemas de su escritura sobre cualquier otro aspecto de la realidad.

Por su parte, desde los años 50, los directores neorrealistas italianos venían mostrando igualmente estilemas autorales, proponiendo un tipo de autor que debía expresar la realidad tal cual era, sin manipulación, permitiendo al espectador interpretarla a su manera. En este sentido, con este género mixto que he propuesto, interrelaciono la obra de varios directores (de auteur y neorrealistas) que, de alguna manera, ejemplifican un debate teórico: por una parte tenemos varios filmes que apelan a una audiencia global, pero no desde un punto de vista hegemónico, sino teniendo en cuenta las peculiaridades vernaculares -y no solo por motivos aparentemente estéticos, como la inclusión de personajes de varias nacionalidades (chinos, africanos, etc.), sino también por la presencia, en la propia estructura del film, de toda una serie de sentimientos (melodramáticos en el mejor sentido) que, por ejemplo, apelan, como mínimo, a gran parte de la comunidad iberoamericana. Por otra parte, este debate alude a la inclusión de otro tipo de directores que, sin dejar de lado la expresión individual, dan más importancia a la fidelidad de la representación de la realidad.

De nuevo, creo que el texto Biutiful es un lugar privilegiado para esta dialéctica entre lo autoral y el realismo, también entre lo global y lo vernacular. En este sentido, los campos vacíos con los que he ilustrado mi artículo más arriba hacen referencia tanto a lo autoral, a modo corriente de consciencia - dado que todo parte del punto de vista de Uxbal-, como a una inclusión de cierto realismo sucio que impregna todo el film y que igualmente está en los momentos más íntimos del personaje, como los de su mirada perdida en el techo expuestos más arriba.

\subsection{Desenlace y redención}

Pero esta dialéctica citada va más allá en el film: si topológicamente la parte más poética y autoral suele estar representada mediante planos contrapicados, centrándose en las partes superiores de las escenas (las manchas en el techo, las mariposas negras, el cielo de Barcelona); el nivel de lo real será, siguiendo esa lógica, mostrado en picado, en las partes más bajas de las posibles en el ecosistema de Uxbal. Ejemplo radical de este otro nivel es el sótano donde morirán los emigrantes chinos (vale recordar que, indirectamente, por culpa de la imprevisión de Uxbal). 


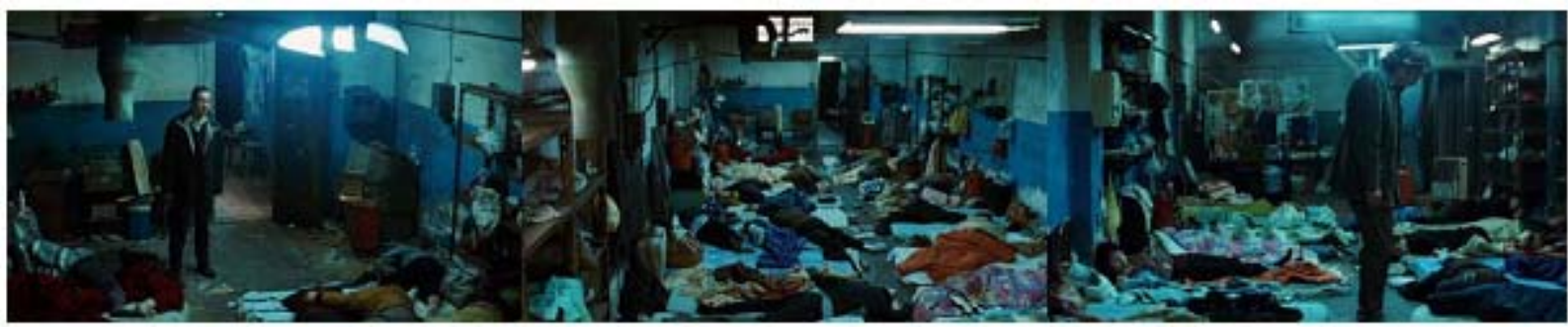

Figura 8. Nivel de lo real en plano picado.

Pero momentos íntimos o poéticos no significan edulcorados: ya he hecho referencia a la sombría cruz y a las simbólicas mariposas negras que predestinan la muerte de Uxbal; pero también en esa parte superior de los espacios que recorre Uxbal nos encontramos con los espíritus de los emigrantes que acaban de morir y que no encuentran la paz; $y$, sobre todo, con otro de los reversos de la Modernidad: la madre avasalladora - en primer lugar, de la madre de sus hijos, Marambra-, la mujer hecha Diosa, apareciendo en un lugar en el que ningún anclaje simbólico es posible, en la discoteca - a modo de escena fantasmática- donde Uxbal va a contarle a su hermano la muerte de los inmigrantes chinos.

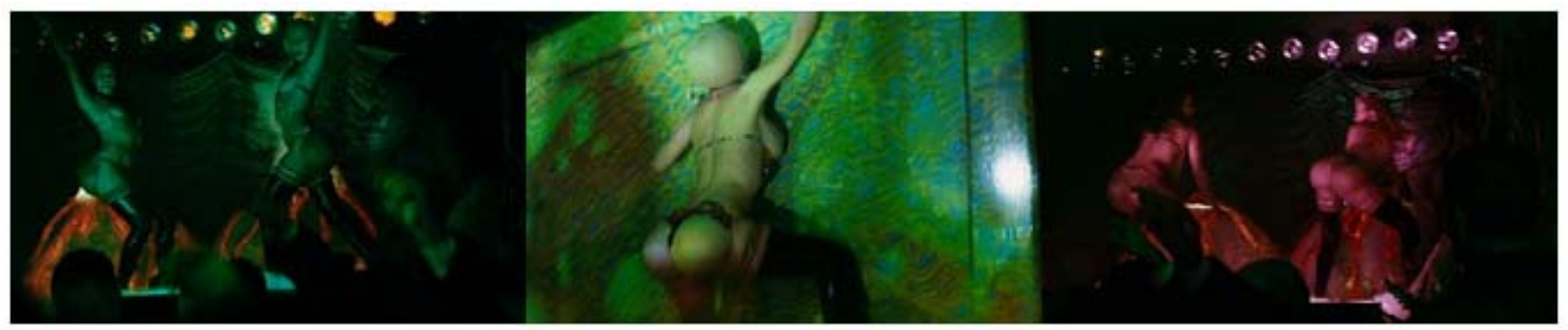

Figura 9. .Sin posibilidad de anclaje simbólico.

Seguramente nunca se ha representado a Barcelona de una forma más cruda y onírica al mismo tiempo, lejos de la ciudad condal de los turistas, o de la Vicky Cristina Barcelona (2008) de Woody Allen. Es decir, no sale la Barcelona de Gaudí -aparece beautiful sin duda; pero es más bien "biutiful"- y, sobre todo, no sale una Sagrada Familia de postal: cuando Uxbal se queda mirándola desde la ventana de la sala de tratamiento del hospital, se la llega a ver en la lejanía todavía en construcción (¿enferma?), en un barrido fantasmal, en cuyo fondo aparece dibujado el otro edificio radicalmente distinto y distintivo de la ciudad, que simboliza esta vez la globalización y cosmopolitismo de Barcelona y su lado más capitalista y hegemónico: la Torre Agbar. Por cierto, de nuevo, entonces, se comprueba cómo Iñárritu reflexiona en todo momento, a la mínima oportunidad, sobre el tema que he propuesto para mi artículo, globalización frente a lo vernacular, el arquitecto postmoderno por excelencia, Jean Nouvel (el mismo que diseñó el MNCARS), frente a otro arquitecto, precursor del modernismo del que inevitablemente bebe Nouvel, Antoni Gaudí, pero que erige su edificio para celebrar a un Dios radicalmente diferente. 


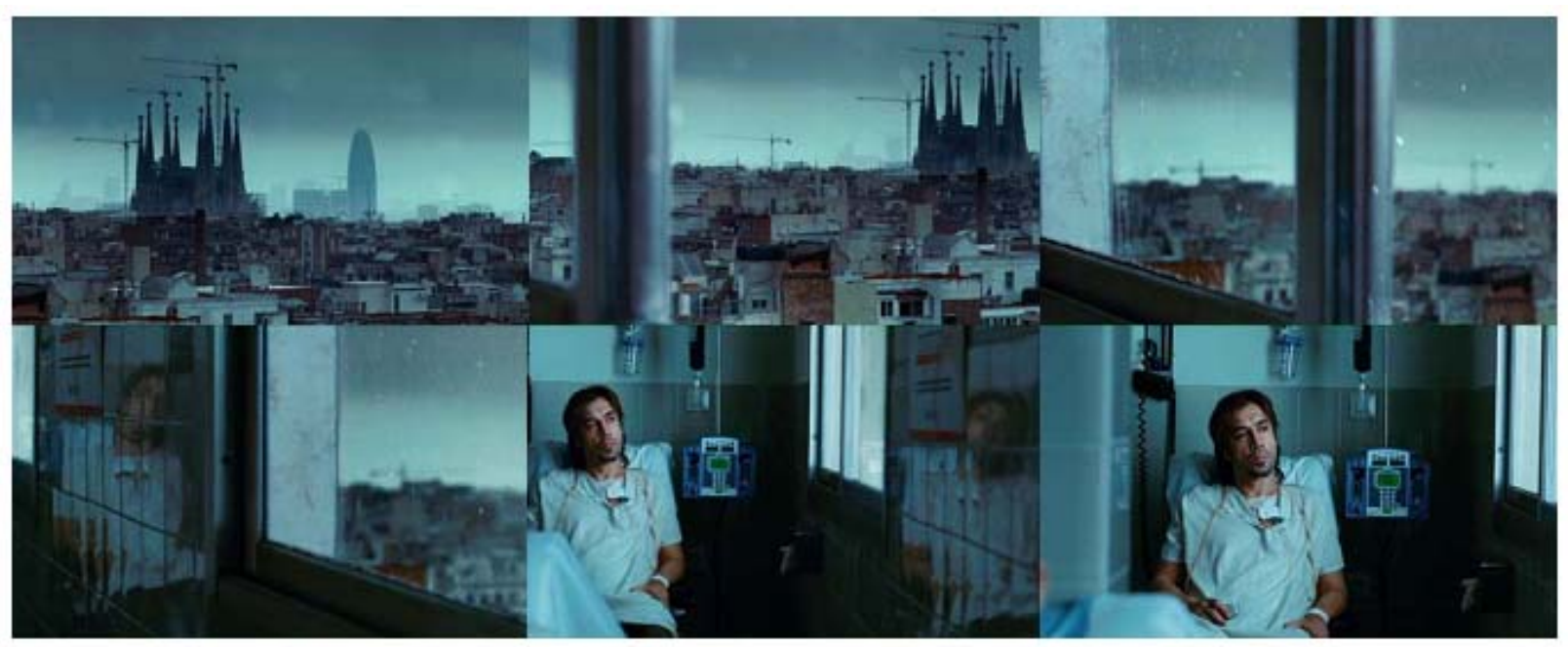

Figura 10. Barcelona is Biutiful.

Este templo simbólico de Barcelona es precisamente lo que parece buscar Uxbal en su deambular por las calles. Es decir, una Ley que le guíe en sus decisiones y, por eso, la trama del padre del que no pudo despedirse se convierte en la clave secreta del film, sobre todo, cuando él mismo sí permite que su hija pueda despedirse de él: a través de un anillo y lo que de promesa puede haber en éste. Ahí cobra sentido, pues, que la película esté enmarcada en esa secuencia a modo de prólogo y epílogo con su derivada en el sueño en la nieve en la que su padre le muestra un camino más allá, en el fuera de campo.

\section{CONCLUSIONES}

Hay, pues, una evolución espiritual del protagonista el cual, a modo de bajada a los infiernos - como el de los inmigrantes ilegales chinos que mueren en el sótano intoxicados por gas- va surcando un paisaje de realismo sucio - muy cercano al primer film de Iñárritu, Amores perros-; pero, al mismo tiempo, va emergiendo un espacio mágico y sobrenatural: ahí tenemos las mariposas negras que aparecen en los momentos más desesperados y reflexivos del personaje. En éstas -como en las piedras que dona a sus hijos- está también la estética que señala el neologismo "biutiful": no una belleza imaginaria sino una trascendente - véase más arriba el tremendo cielo barcelonés surcado de negras aves que se ha utilizado en el tráiler de la película. A ello ayuda la fotografía de Rodrigo Prieto, que ha sido director de fotografía de todas sus películas, así como de Brokeback Mountain (Ang Lee, 2005, otro world cinematographer de pro) entre otras.

Esta estética enrarecida cristaliza, asimismo, en el nombre del personaje: Uxbal es un nombre extraño, como extraña sería aquella mañana en la que Iñárritu y sus hijos se preparaban el desayuno escuchando el Concierto de piano en sol mayor de Maurice Ravel que les hizo llorar: esa misma mañana un personaje llamado Uxbal llamó a la puerta de la imaginación del director. 
He querido interrelacionar varios conceptos que creo que sobrevuelan la cinematografía de Iñárritu y que, de manera especial, cristalizan en Biutiful. Este film, lejos de ser un film más, en opinión de muchos, a olvidar en su filmografía, rebusca en las contradicciones de la globalización y sus efectos hegemónicos, frente a las imprescindibles manifestaciones vernaculares que no dejan de enriquecer aquello que hemos intentado analizar someramente, llámese a éste World Cinema o melodrama de autor.

\section{REFERENCIAS}

Benjamin, W. (1973). La obra de arte en la era de su reproducibilidad técnica, en Discursos Interrumpidos I. Madrid: Editorial Taurus.

Cano-Gordón, C. (2010). Guillermo Arriaga, en Revista CineAdictos, no 95 (agostoseptiembre). Consultado el 29 de Marzo del 2010, Disponible en:

http://mexicanadecomunicacion.com.mx/rmc/2011/02/23/guillermo-

arriaga/\#axzz1L1vgbLiV

Eco, U. (1965). Apocalípticos e integrados. Barcelona: Editorial Lumen.

González-Requena, J. (2006). Clásico, manierista, postclásico. Los modos del relato en el cine de Hollywood. Valladolid: Castilla Ediciones.

González-Requena, J. (2007). Douglas Sirk. La metáfora del espejo. Madrid: Cátedra.

González-Requena, J. (2008). Amor loco en el jardín. La diosa que habita el cine de Luis Buñuel. Madrid. Editorial Adaba.

Hansen, M. B. (1999). The Mass Production of the Senses: Classical Cinema as Vernacular Modernism, en Revista Modernism/Modernity, 2(6), p. 59-77. Consultado el 5 de Abril del 2010, Disponible en:

http://elenarazlogova.org/hist615/pdfs/hansen.pdf

Krauze, D. (2011): Biutiful, o los límites del azar, en Revista Letras Libres, (enero), p. 64-65. Consultado el 5 de Abril del 2010, Disponible en:

www.letraslibres.com/index.php?art $=15211 \&$ rev $=2$ )

Mac Donald, D. (1969): Masscult and Midcult, en La industria de la cultura, p. 67-156. Madrid: Editorial Alberto Corazón.

Torres-Hortelano, L. J. (2009). Auter Melodrama, en Directory of World Cinema: Spain. Londres: Editorial Intellect. 
Lorenzo J. Torres Hortelano 